\title{
Research on the Maturity Model of Conflict Management in Engineering Project
}

\author{
Wan Zhang, Hui Zhao \\ School of Management, Qingdao Technological University, Qingdao, China \\ Email: zwan0318@163.com
}

Received October 2013

\begin{abstract}
Integrated Project Management Maturity proposed a new concept. It is "Project Conflict Management Maturity". It established a new concept of maturity level, established an evaluation index system on Project Conflict Management Maturity and used the multi-level fuzzy comprehensive evaluation method combined with the Project Management Maturity model to construct the maturity model of Project Conflict Management. Then, through numerical examples, it evaluated the score of object, got the maturity level of conflict management of the study project, verified the feasibility of the model for solving Project Conflict Management, provided some bases for solving problems of Project Conflict Management and had a certain practical significance about this problem.
\end{abstract}

\section{Keywords}

Engineering Project; Conflict Management; Multi-Level Fuzzy Comprehensive Evaluation

\section{Introduction}

At present, China and various countries have carried out the project management of a wide range and in-depth study. Because project management has always been a hot research, it can make the development of a country on a higher level. For project management, the conflict management is a crucial aspect. Project Conflict Management is particularly important for a project. If people cannot resolve the conflict effectively, it will affect all aspects of the project. Only resolving the conflicts successfully, could the desired effect be achieved. Project Conflict is a project from start to finish produced in interpersonal process, resources, implementation and planning. And conflict management refers to the coordination and resolution of the conflict.

Although many scholars study the Project Conflict Management, the literatures for the overall Project Management Maturity of the conflict are not many. For example, Kang Wei [1] had a study on the project management of conflict. It did not study the Project Conflict Management on overall progress, so people couldn't judge the conflict management of the project on a kind of level. Based on this, the author combined the concept of Project Management Maturity and proposed the concept of Project Conflict Management Maturity, defined the concept of Project Management Maturity level, used fuzzy comprehensive evaluation method to build a maturity level evaluation model combined with numerical example to verify the feasibility of the model. 


\section{The Project Management Conflict Maturity Levels Are Defined}

Maturity is something rising levels of a process of development, it must be pointed out that the ability to continue to improve over time, so that organizations can continue to achieve success in the competition [2]. Project Management Maturity refers to an organization in the selection and management of the project embodied on the overall level, project management is the ability to measure, evaluate, improve and enhance the ways and means, as well as organizations with a development project management capability tool [3]. Author based on two concepts given above as well as various types of Project Management Maturity, conflict management project related research, define the Project Management Maturity as a project coordination and resolve conflict degree of perfection.

In the above based on the concept of maturity, the Project Management Maturity conflict is divided into the following four levels (Table 1).

Perfect levels: when the score of Project Conflict Management Maturity between 3 to 4, is the perfect level, which means that the project coordination and conflict management problems solved perfectly, the project proceed smoothly, fully able to achieve the desired results.

Specification levels: when the score of Project Conflict Management Maturity between 2 to 3, is regulate the level, which means that the conflict is properly managed project, the project normally, generally unaffected;

Progress stage: when the score of Project Conflict Management Maturity between1 to 2, in order to progress in level, which means that conflict to conduct an appropriate coordination and communication, but not very effective, is being progressive stage, the smooth progress of the project some effects may not reach the expected project results;

Confusion levels: when the score of Project Conflict Management Maturity less than confusing level, which means that coordination and resolve conflict shall not be treated, leading to various aspects of the project had a negative impact, delayed the project proceed smoothly.

\section{Construction of Evaluation Index System}

In order to analyze and evaluate the Project Conflict Management, we establish the corresponding evaluation index system. Learn from the literature [4,5], the Project Conflict Management Maturity level indicators have four, according to an index is further divided into 18 two indicators, each indicator is an indicator of two segments, through the evaluation of indicators in each segment to determine the level indicators, in the end to obtain the target layer, as shown in Table 2.

\section{Build Models}

There are no specific methods for assessing perfect level of Project Conflict Management, so according to the established Project Management Maturity index system of conflict, it not only as a whole has a multilevel nature, but also its two indicators have inaccuracies, so the author uses a multi-level fuzzy comprehensive evaluation method [6-8]. Analytic Hierarchy Process (AHP) is a effective method to solve many indicators and multilevel nature, fuzzy comprehensive evaluation method is a quantitative analysis of the indicators, it is very suitable for the problem of maturity, so we use the two kinds of methods to build model simultaneously.

Using AHP, the evaluation at all levels were set at the target layer $(W)$, an index layer $\left(U_{i}\right)$ and two index layer $\left(V_{i j}\right), i=1,2,3,4 ; j=1,2, \ldots, n_{i}$. $U$ is a set of evaluation form for above, denoted by $U=\left\{U_{1}, U_{2}, U_{3}, U_{4}\right\}$; $V_{i}$ is a set of $V_{i j}$, denoted by $V_{i j}=\left\{V_{i 1}, V_{i 2}, \ldots, V\right\}$. According to the optional multi-level fuzzy comprehensive evaluation method to establish an Project Conflict Management Maturity Model follow these steps:

1) Setting evaluation grade standards. The $V_{i j}$ into "excellent”, "good”, “medium” and "poor" four assessment levels, giving each level corresponds score: 4 points, 3 points, 2 points and 1 point. Because of sometimes the actual index level between two adjacent level, then this case on the intermediate scores were given, that is 3.5 points, 2.5 points and 1.5 points, with higher scores corresponding to illustrate aspects of conflict manage-

Table 1. Project Management Maturity index values.

\begin{tabular}{ccccc}
\hline Level & Perfect & Specification & Progressive & Confusion \\
\hline Standard & $3-4$ & $2-3$ & $1-2$ & $<1$ \\
\hline
\end{tabular}


Table 2. Project Conflict Management Maturity evaluation index system.

\begin{tabular}{|c|c|c|}
\hline Target layer & An index layer & Two index layer \\
\hline \multirow{18}{*}{$\begin{array}{l}\text { Research on the } \\
\text { Maturity Model } \\
\text { of Conflict } \\
\text { Management } \\
\text { in Engineering } \\
\text { Project }\end{array}$} & \multirow{9}{*}{$\begin{array}{l}\text { Interpersonal } \\
\text { conflict }\end{array}$} & Exchange of information is not in place \\
\hline & & Lack of good team building \\
\hline & & Organizational level, management span unscientific \\
\hline & & Clear division of tasks \\
\hline & & Leadership skills and styles defects \\
\hline & & Values \\
\hline & & Conflict of Interest \\
\hline & & Interpersonal skills \\
\hline & & Personality \\
\hline & \multirow{4}{*}{$\begin{array}{l}\text { Resource } \\
\text { conflicts }\end{array}$} & Lack of qualified staff \\
\hline & & Lack of professional and technical personnel \\
\hline & & Limited funds \\
\hline & & Shortage of resources \\
\hline & \multirow{2}{*}{$\begin{array}{l}\text { Executive } \\
\text { Conflict }\end{array}$} & Implementation modalities and implementation modalities of the traditional conflict \\
\hline & & Handling conflicts the traditional approach \\
\hline & \multirow{3}{*}{ Plan conflict } & Actual time of conflict and the original scheduled time \\
\hline & & Actual costs and the cost of the original plan conflict \\
\hline & & Actual quality and the quality of the original plan conflict \\
\hline
\end{tabular}

ment doing better, all levels of indicators so on.

2) Determine the $U_{i}$ and $V_{i j}$ corresponding weights. Suppose $U_{i}$ obtains an index weight of $\alpha_{i}$, the index weight vector $\mathrm{A}=\left(\alpha_{1}, \alpha_{2}, \alpha_{3}, \alpha_{4}\right)$, met $\alpha_{\mathrm{i}}>0 ; \sum_{\mathrm{i}=1}^{4} a_{i}=1$; two indicators $V_{i j}$ weight distribution of $\alpha_{i j}$, the index weight vector satisfied: $a_{i j} \geq 0 . \sum_{\mathrm{j}=1}^{n i} a_{i j}=1\left(i=1,2,3,4 ; j=1,2, \ldots, n_{i}\right)$

3) Fuzzy evaluation matrix is determined. the relevant experts in the field of conflict management issues for the project to assess the extent of perfection. Need 8 these experts. Because different evaluators assessment can be made different, so the results of the evaluation can only be made on the $i$-th index $j$-evaluation scale to the extent possible to show. This may be called the degree of membership. Membership calculation in the following methods: $\mathrm{r}_{i j k}\left(i=1,2,3,4 ; j=1,2, \ldots, n_{i} ; k=1,2, \ldots, 4\right)$ is the membership of $U_{i j}$ for the first $k$-level reviews $V_{k}$. Statistical results of the experts rated organize, index $U_{i j}$ have $V_{i j 1}$ for a $V_{1}$-level reviews, $V_{i j 2}$ a $V_{2}$-level reviews and so on, then for $i=1,2,3,4$ are:

$$
\mathrm{r}_{i j k}=v_{i j k} / \sum_{k=1}^{4} v_{i j k}
$$

According $r_{i j k}$ value can be obtained by evaluation of an index for each grade of membership consisting of row vectors $r_{i j}$ and has been composed by the $r_{i j}$ evaluation matrix $R_{i}$ :

$$
R_{i}=\left[\begin{array}{llll}
r_{1 j 1} & r_{1 j 2} & r_{1 j 3} & r_{1 j 4} \\
r_{2 j 1} & r_{2 j 2} & r_{2 j 3} & r_{2 j 4} \\
r_{3 j 1} & r_{3 j 2} & r_{3 j 3} & r_{3 j 4} \\
r_{4 j 1} & r_{4 j 2} & r_{4 j 3} & r_{4 j 4}
\end{array}\right]
$$


4) Evaluation and comprehensive evaluation to determine the vector values are calculated.

a) Univariate fuzzy judgment.

According to the obtained single factor fuzzy evaluation matrix $R_{i}$, calculate the single factor evaluation vector $B_{i}: \quad B_{\mathrm{i}}=\mathrm{Ri}_{\mathrm{i}} \times A_{i}=\left(b_{i 1}, b_{i 2}, b_{i 3}, b_{i 4}\right)$.

b) Multi-factor comprehensive evaluation.

According to this method, a higher level of $B_{i}$ constituting the matrix $R: \quad R=\left[\begin{array}{llll}B_{1} & B_{2} & B_{3} & B_{4}\end{array}\right]^{T}$. The resulting evaluation results $B=A \times R=\left(b_{1}, b_{2}, b_{3}, b_{4}\right)$ is to get the Project Management Maturity conflict fuzzy comprehensive evaluation set. $B$ is not only considered as an indicator impact, but also considered as the impact of the two indicators, so they can be more reasonable evaluation index.

5) Calculate the comprehensive evaluation value

Composite indicator is calculated as $M=B \times C^{T}$. $M$ is the Project Management Maturity conflict evaluation value; $B$ for the final comprehensive evaluation vector; $C$ clash for the Project Management Maturity Rank scores row vector matrix, $C=(4,3,2,1)$, corresponding to the maturity level of evaluation were perfectly level, normative level, progress and confusion grade level. $C^{T}$ is the transpose of the matrix $C$.

\section{Case}

Based on the above the established model to analyze an example of a project validation. The project investment and scale, from pre-planning to the construction process has been concern that if the project to be successfully completed, will provide convenience for a lot of people, so because of the project severe degree and level of concern, the project needs to be conflict studies to the smooth conduct of the project to achieve the desired results. The problem of conflict management project evaluation steps as follows:

$$
R_{1}=\left[\begin{array}{llll}
0.375 & 0.250 & 0.125 & 0.250 \\
0.500 & 0.125 & 0.250 & 0.125 \\
0.250 & 0.375 & 0.125 & 0.250 \\
0.250 & 0.375 & 0.250 & 0.125 \\
0.375 & 0.125 & 0.375 & 0.125 \\
0.125 & 0.125 & 0.625 & 0.125 \\
0.625 & 0.125 & 0.000 & 0.250 \\
0.250 & 0.375 & 0.250 & 0.125 \\
0.250 & 0.125 & 0.375 & 0.250
\end{array}\right] \ldots
$$

1) Based on multi-level fuzzy comprehensive evaluation method, establish a group of authoritative expert group evaluation index weights. In this example, assume that select eight experts involved in the evaluation, the score after the AHP analysis, and ultimately determine the weights are as follows:

$$
\mathrm{A}=(0.2772,0.1601,0.0954,0.4673) \ldots \mathrm{A}_{4}=(0.6370,0.1047,0.2583)
$$

2) Given in the expert combination of these scoring criteria and the actual situation of the project, in order for all of two indicators were evaluated to establish evaluation matrix and vector be judged accordingly.

$$
B_{1}=A_{1} * R_{1}=(0.3543,0.2497,0.2039,0.1921) \ldots B_{4}=(0.2500,0.3235,0.2561,0.1704)
$$

3) Comprehensive evaluation vector calculation

$$
B=A * R=A *\left[\begin{array}{cccc}
B_{1} & B_{2} & B_{3} & B_{4}
\end{array}\right]^{T}=(0.2947,0.2800,0.2343,0.1910)
$$

4) Computational Engineering Project Management Maturity conflict comprehensive evaluation value. The result of Project Conflict Management is $M=B \times C^{T}=2.6784$, combined with the results shown in Table 1, this Project Conflict Management Maturity value is between 2 to 3, the level is specification, this project's conflict is properly managed, normally and generally unaffected.

\section{Summary}

Conflict management issues bearing on the success of a project can proceed smoothly. The project can achieve 
the desired effect. Conflict Management Maturity is reflected in a conflict management project success. But for how to evaluate a Project Conflict Management degree of perfection is not having a clear way. The author proposed the new concept of Project Conflict Management Maturity, and the establishment of conflict management maturity index system, combined with multi-level fuzzy comprehensive evaluation method conflict constructed Project Management Maturity model, and a numerical example, the project drawn conflict management maturity model feasible. Therefore, using the project conflict management indicators to judge the value of conflict management maturity level, the persons can make the project not only more rational in decision-making, but also better in preventing, transforming and resolving conflicts..

\section{References}

[1] Kang, W. (2011) Research on Conflict Management of Engineering Project of CNPC in South America. China University of Petroleum, Qing Dao (in Chinese).

[2] (America) Project Management Institute (2009) Organizational Level Project Management Maturity Model (OPM3). 2nd Edition, Electronic Industry Press, Beijing.

[3] (America). Harold Author, Zhang, Z.H. and Lv, Y.H. (2002) Project Management Strategic Planning: The Application of Project Management Maturity Model. Electronic Industry Press, Beijing.

[4] Zhang, X.L. (2008) Study of Organization Conflict Management in Project Management. Chongqing University, Chongqing (in Chinese).

[5] Han, L.M. (2007) Research on Fuzzy Evaluation of ERP Project Conflict Management. China Management Informationization, 10 (in Chinese).

[6] Gobeli, D.H., Koenig, H.F. and Bechinger, I. (1998) Managing Conflict in Software Development Teams: A Multilevel Analysis. Journal of Product Innovation Management, 15, 423-435.

[7] Su, S.W. (2012) Study and Application of Fuzzy Comprehensive Evaluation Model in Project Management Maturity of Municipal Investment. Central South University, Changsha (in Chinese).

[8] Xiao, T.M. (2013) Based on AHP and Fuzzy Comprehensive Evaluation of Investment Performance Study of Wild Hill Afforestation YaMaLiKeShan in XinJiang as an Example. Studies of Finance and Economics (in Chinese). 